Check for updates

Cite this: RSC Adv., 2021, 11, 12649

\section{Bimetallic cobalt-iron diselenide nanorod modified glassy carbon electrode: an electrochemical sensing platform for the selective detection of isoniazid $\dagger$}

\begin{abstract}
Sundas Sultan, ${ }^{a}$ Muhammad Zulqarnain, ${ }^{a}$ Afzal Shah, (D) *a Naveeda Firdous, ${ }^{a}$ Jan Nisar, (D) ${ }^{b}$ Muhammad Naeem Ashiq, ${ }^{c}$ Esraa M. Bakhsh ${ }^{d}$ and Sher Bahadar Khan ${ }^{d}$

The increasing demand of a sensitive and portable electrochemical sensing platform in pharmaceutical analysis has developed widespread interest in preparing electrode materials possessing remarkable properties for the electrochemical determination of target drug analytes. Herein, we report the synthesis, characterization and application of bimetallic cobalt-iron diselenide ( $\mathrm{FeCoSe}_{2}$ ) nanorods as electrode modifiers for the selective detection of a commonly used anti-tuberculosis drug Isoniazid (INZ). We prepared $\mathrm{FeCOSe}_{2}$ nanorods by a simple hydrothermal route and characterized these by X-ray diffraction (XRD), scanning electron microscopy (SEM), transmission electron microscopy (TEM), energy dispersive $X$-ray spectroscopy (EDX) and temperature-programmed reduction (TPR) techniques. The electrochemical characterization of $\mathrm{FeCOSe}_{2}$ modified GCE was performed by cyclic voltammetry (CV) and square wave anodic stripping voltammetry (SWASV). Under optimized experimental conditions, a linear current-concentration response was obtained for INZ in the range of 0.03-1.0 $\mu \mathrm{M}$, with very low limit of detection $1.24 \times 10^{-10} \mathrm{M}$. The real applicability of the designed $\mathrm{FeCoSe}_{2} / \mathrm{GCE}$ sensing platform was adjudicated by the detection of INZ in biological samples.
\end{abstract}

Received 27th February 2021 Accepted 24th March 2021

DOI: $10.1039 / d 1 r a 01572 a$

rsc.li/rsc-advances techniques have their own advantages but every technique has some limitations. Therefore, efforts are underway to search for effective tools on case to case basis. Electrochemical techniques are attracting attention owing to their peculiar features of being cheaper, easy to operate, portable, sensitive and selective. Many research teams have employed modified electrodes for INZ detection. ${ }^{\mathbf{1 0 - 1 5}}$ But the modified electrodes suffer from serious fouling effects that can be minimized by the right selection of supporting electrolyte and type of material used for electrode modification. ${ }^{16-19}$

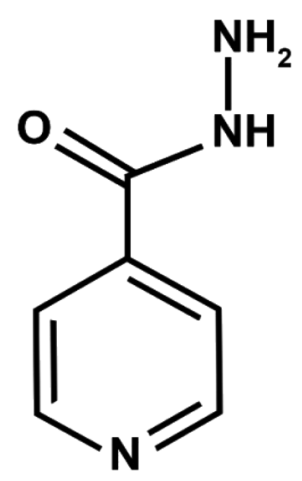

Fig. 1 Chemical structure of isoniazid (INZ).

\footnotetext{
${ }^{a}$ Department of Chemistry, Quaid-i-Azam University, Islamabad, 45320, Pakistan. E-mail: afzals_qau@yahoo.com

${ }^{b}$ National Centre of Excellence in Physical Chemistry, University of Peshawar, Peshawar, 25120, Pakistan

'Institute of Chemical Sciences, Bahauddin Zakaryia University, Multan 6100 , Pakistan

${ }^{d}$ Department of Chemistry, King Abdulaziz University, P. O. Box 80203, Jeddah 21589, Saudi Arabia

$\dagger$ Electronic supplementary information (ESI) available. See DOI: 10.1039/d1ra01572a
} iluminescence, colorimetry, capillary electrophoresis, fluorimetry, chemometry, titrimetry, polarography, and spectrophotometry are used for INZ analysis..$^{5-9}$ All these 
Metal chalcogenides and specifically metal diselenides $\left(\mathrm{MSe}_{2}\right)$ have attained great attention for ongoing research. ${ }^{20-22}$ The higher metallic character of Se in chalcogenides might attributed to their extraordinary physical and electrochemical properties. In recent years, various metal selenides $\mathrm{MSe}_{2}(\mathrm{M}=$ $\mathrm{Co}, \mathrm{Fe}, \mathrm{Mo}, \mathrm{Cu}$, and $\mathrm{Ni}$ ) have been extensively applied as effective electrocatalysts in electrochemical applications. ${ }^{23-26}$ Among various metal diselenides, $\mathrm{FeSe}_{2}$ and $\mathrm{CoSe}_{2}$ have been mostly investigated due to their excellent electrical conductivity, low diffusion length for ion/electron, high specific capacitance, mechanical stability, low charge transfer resistance, and significant recycling ability. ${ }^{27-30}$ In fact, $3 d$ electrons with a low spin in Co metal facilitate the metallic characteristic of $\mathrm{CoSe}_{2}$ which leads to increase in the charge transfer during the electrocatalytic process. The electrocatalytic activity of $\mathrm{CoFeSe}_{2}$ alloy could be enhanced due to the synergistic effect between Fe and $\mathrm{CoSe}_{2}$. The hetero-metallic bond formation in bimetallic alloys results in the tuning of the bonding patterns of catalyst surface with the reactant molecules (INZ). ${ }^{31}$ The strong metal-metal interactions in bimetallic systems also modify the electrical and mechanical properties which make them favorable for different electrocatalytic applications.

Cobalt diselenide nanobelts grafted on carbon fiber presented a robust electrochemical performance that can be correlated to the synergistic effect between $\mathrm{CoSe}_{2}$ and carbon fiber besides 3D cathode architecture providing catalytic stability. ${ }^{32}$ Liu et al. successfully fabricated $3 \mathrm{D} \mathrm{Ni}_{(1-x)} \mathrm{Co}_{x} \mathrm{Se}_{2}$ mesoporous nanosheet on Ni foam with tunable stoichiometry. ${ }^{33}$ The collective effects of special morphological design and electronic structure engineering enable the integrated highest catalytic activity and outstanding stability in a wide $\mathrm{pH}$ range. Recently, Zheng et al., studied phase transition of $\mathrm{CoSe}_{2}$ from cubic to orthorhombic with appropriate doping of phosphorus. ${ }^{34}$ The striking electrocatalytic performance can be attributed to the favorable electronic structure and local coordination environment created by this doping-induced structural phase transition strategy. In literature, most of the studies are focused on electrochemical oxidation/reduction reactions using cobalt diselenide, whereas electrochemical studies using composite materials of cobalt diselenide are rather limited.

Herein, we report $\mathrm{FeCoSe}_{2}$ nanorods modified GCE for electrochemical detection of INZ in neutral media. Our objective is to use comparatively cheaper electrode modifier for more sensitive detection of INZ. The morphological features of metal nanorods provide excellent electrochemical sensing platforms due to high surface area and higher exposure of specific crystal facets. To the best of our knowledge, no previous work is reported on the use of $\mathrm{FeCoSe}_{2} / \mathrm{GCE}$ for the electroanalytical detection of INZ. To get a robust electroanalytical signal for INZ on the $\mathrm{FeCoSe}_{2} / \mathrm{GCE}$, we have optimized experimental conditions. We have validated the real-world applicability of $\mathrm{FeCoSe}_{2} /$ GCE in the real samples.

\section{Experimental section}

\section{Chemicals and apparatus}

Isoniazid $\left(\mathrm{C}_{6} \mathrm{H}_{7} \mathrm{~N}_{3} \mathrm{O}\right.$, Merck, $\left.\geq 99 \%\right)$, iron(II) chloride tetrahydrate $\left(\mathrm{FeCl}_{2} \cdot 4 \mathrm{H}_{2} \mathrm{O}\right.$, Merck, $\left.\geq 99 \%\right)$, cobalt(II) chloride hexahydrate $\left(\mathrm{CoCl}_{2} \cdot 6 \mathrm{H}_{2} \mathrm{O}\right.$, Merck, 98\%), sodium hydroxide $(\mathrm{NaOH}$, Merck, $\geq 97 \%)$, EDTA $\left(\mathrm{C}_{10} \mathrm{H}_{14} \mathrm{~N}_{2} \mathrm{Na}_{2} \mathrm{O}_{8} \cdot 2 \mathrm{H}_{2} \mathrm{O}\right.$, Merck, 99\%), boric acid $\left(\mathrm{H}_{3} \mathrm{BO}_{3}\right.$, Merck, $\left.\geq 99.5 \%\right)$, and phosphoric acid $\left(\mathrm{H}_{3} \mathrm{PO}_{4}\right.$, Merck, $\left.\geq 99 \%\right)$ were purchased and used as received without any purification. The Britton Robinson buffer (BRB) of pH 7 was used as supporting electrolyte which was prepared by mixing $0.04 \mathrm{M} \mathrm{H}_{3} \mathrm{BO}_{3}, 0.04 \mathrm{M} \mathrm{H}_{3} \mathrm{PO}_{4}$, and $0.04 \mathrm{M} \mathrm{CH}_{3} \mathrm{COOH}$. The $\mathrm{pH}$ of BRB was adjusted to 7 by adding $0.2 \mathrm{M} \mathrm{NaOH}$ solution. All the solutions were made in doubly distilled water.

\section{Instrumentation}

XRD analysis was performed on Rigaku D/max 2500 with a radiation source $\mathrm{Cu} \mathrm{K} \alpha 1(\lambda=1.54056 \AA)$. SEM and TEM images of the prepared samples were recorded on electron microscope JEM 2100 (USA) equipped with EDS unit for chemical analysis. The accelerating voltage was kept at $10 \mathrm{kV}$ and 100

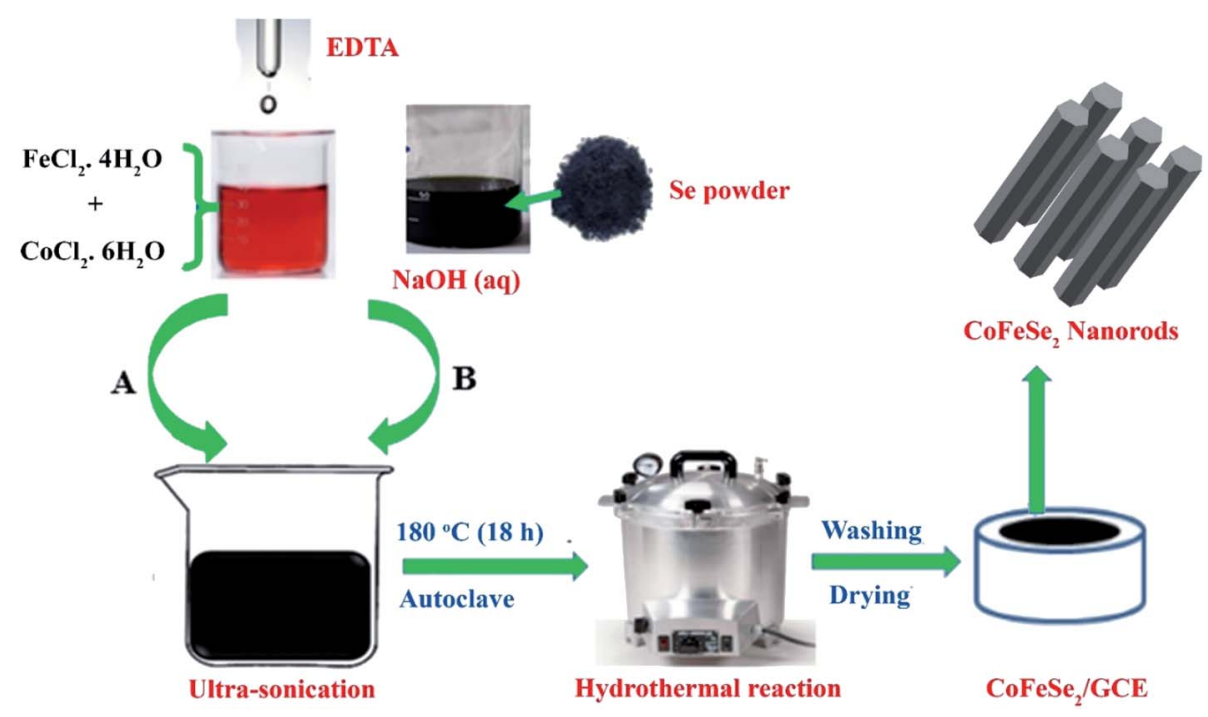

Fig. 2 Schematic representation of the synthesis of $\mathrm{CoFeSe}_{2}$ modification. 
$\mathrm{kV}$ for SEM and TEM images, respectively. TPR analysis of the synthesized nanocomposite was performed on ChemiSorb 2750 (Micromeritics-USA) to evaluate the different metallic phases and alloying effects of constituent metals. The surface area analysis was performed using Sorptometer Kelvin 1042 (Costech Instruments) at liquid $\mathrm{N}_{2}$ temperature $\left(-196^{\circ} \mathrm{C}\right)$ after degassing the samples at $200{ }^{\circ} \mathrm{C}$ for $2 \mathrm{~h}$.

\section{Catalyst preparation}

At first, $\mathrm{CoSe}_{2}$ was synthesized by following the hydrothermal route as shown in Fig. 2. The solution labeled as A was prepared by mixing $0.8 \mathrm{mmol}$ of $\mathrm{CoCl}_{2} \cdot 6 \mathrm{H}_{2} \mathrm{O}$ with $2 \mathrm{~mL}$ of $0.5 \mathrm{M}$ ethylene diamine tetra-acetic acid (EDTA). Another solution labeled as B was prepared by mixing $0.162 \mathrm{mmol}$ of Se powder in $8 \mathrm{~mL}$ of $3.3 \mathrm{M}$ $\mathrm{NaOH}$. Both solutions $\mathrm{A}$ and $\mathrm{B}$ were then mixed via ultrasonication. After that, the resultant mixture was shifted to autoclave and kept at $180{ }^{\circ} \mathrm{C}$ for $18 \mathrm{~h}$ for the hydrothermal reaction. Similarly, $\mathrm{FeCoSe}_{2}$ bimetallic catalyst was prepared by adding $0.4 \mathrm{mmol}$ of $\mathrm{FeCl}_{2} \cdot 4 \mathrm{H}_{2} \mathrm{O}$ to the above mentioned solution A. In each case, the black product was collected and washed with deionized water followed by air drying. The total quantity of metal sources $(\mathrm{Fe}+\mathrm{Co})$ was kept very low and constant $(0.8 \mathrm{mmol})$. Finally, feeding ratios of metals was further confirmed by EDX.

\section{Electrode fabrication}

Before each electrochemical analysis, GCE was polished using alumina powder $(0.05 \mu \mathrm{m})$ and carefully washed in an ultrasonic bath with doubly distilled water, followed by a mixture of acetone and nitric acid $(1: 1)$ mixture, and finally washed by doubly distilled water and dried in a desiccator. The $1 \mathrm{mg}$ of $\mathrm{FeCoSe}_{2}$ was dispersed in $1 \mathrm{~mL}$ of isopropanol via ultrasonication for 30 minutes to achieve uniform dispersion. Then, $5 \mu \mathrm{L}$ of $\mathrm{FeCoSe}_{2}$ solution was drop casted over the polished surface of bare GCE $\left(0.07 \mathrm{~cm}^{2}\right)$. The fabricated electrode was first dried at room temperature for 20 minutes and then completely dried in the oven at $50{ }^{\circ} \mathrm{C}$ for 30 minutes. The $\mathrm{FeCoSe}_{2} / \mathrm{GCE}$ was then employed for electrochemical analysis of INZ under optimized conditions.

\section{Electrochemical characterization}

Cyclic voltammetry and SWASV measurements were performed at room temperature on potentiostat Gamry interface 1000. The three electrode setup was used for electrochemical studies. Ag/ $\mathrm{AgCl}(3 \mathrm{M} \mathrm{KCl})$, a platinum wire and modified GCE were used as reference, counter and working electrodes respectively. Measurement of $\mathrm{pH}$ of solutions was done using INOLAB $\mathrm{pH}$ meter. The INZ concentration was quantified by assessing oxidation peak current values using the SWASV technique. SWAS voltammograms were recorded under optimized conditions (i.e., deposition voltage of $0.0 \mathrm{~V}$ and deposition time of $90 \mathrm{~s}$ by using both pure GCE and modified $\mathrm{FeCoSe}_{2} / \mathrm{GCE}$ electrodes. For voltammetric investigations experimental conditions were optimized by varying: scan rate, volume of catalyst suspension for electrode fabrication, $\mathrm{pH}$, and buffer solution. These optimizations were done and the best current response was obtained in a medium of $\mathrm{pH} 7$ using catalyst suspension of $5 \mu \mathrm{L}$ for electrode modification. Prior to each measurement, pre- conditioning was done in consecutive 20 runs in the respective potential window to reduce signal to noise ratio.

\section{Results and discussion}

\section{XRD analysis}

Fig. 3 illustrates the XRD pattern of the synthesized $\mathrm{FeCoSe}_{2}$ bimetallic nanocatalyst. The sharp and intense peaks of XRD show that the synthesized material has high crystallinity. The diffraction peaks at $2 \theta \sim 30.71^{\circ}, 34.37^{\circ}, 35.8^{\circ}, 47.8^{\circ}, 50.41^{\circ}, 53.33^{\circ}$, and $55.3^{\circ}$ in the XRD spectra of $\mathrm{FeCoSe}_{2}$ correspond to (101), (110), (120), (211), (002), (031), and (131) hkl planes, respectively (Powder Diffraction Standard Database: JCPDS \# 21-0432).

\section{Surface area analysis}

To assess the surface properties such as the specific surface area and pore particularity, $\mathrm{CoFeSe}_{2}$ nanocomposite was further explored by $\mathrm{N}_{2}$ adsorption-desorption isotherms as shown in Fig. 4. A typical type IV isotherm (Fig. 4A) with $\mathrm{H} 3$ hysteresis loop between 0.4 and $0.8 P / P_{\mathrm{o}}$ reveals the mesoporous nature of the material as per IUPAC classification. ${ }^{35}$ The BET surface area of $\mathrm{CoFeSe}_{2}$ nanocatalyst was found to be $93.14 \mathrm{~m}^{2} \mathrm{~g}^{-1}$. The specific surface area is highly influenced by the surface morphologies and internal porous structures. Besides, the pore size distribution curve (Fig. 4B) was derived from the desorption isotherm by applying the Barret-Joyner-Halenda (BJH) method. Narrow scattering of pores was obtained with the maximum distribution of pores with a size of $5.5 \mathrm{~nm}$, reflecting a unimodal behavior. The large value of the BET area and distinct mesoporous nature contributed towards introducing more active sites which were later manifested by optimum electrochemical sensing of isoniazid over the electrode surface modified with this synthesized catalyst.

\section{Morphological characterizations}

SEM images of $\mathrm{FeCoSe}_{2}$ (Fig. 5(A-C)) indicate the presence of $\mathrm{FeCoSe}_{2}$ nanorods with the diameter ranging from 40 to $90 \mathrm{~nm}$ which is suitable for electrochemical applications. It displayed the uniform distribution of $\mathrm{FeCoSe}_{2}$ nanorods with no agglomeration high metal dispersion of this optimal catalyst

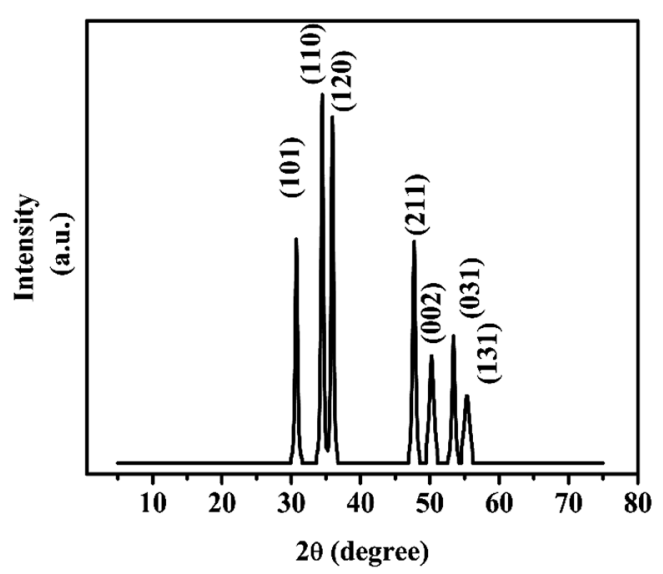

Fig. 3 XRD pattern of the synthesized $\mathrm{FeCoSe}_{2}$ bimetallic catalyst. 

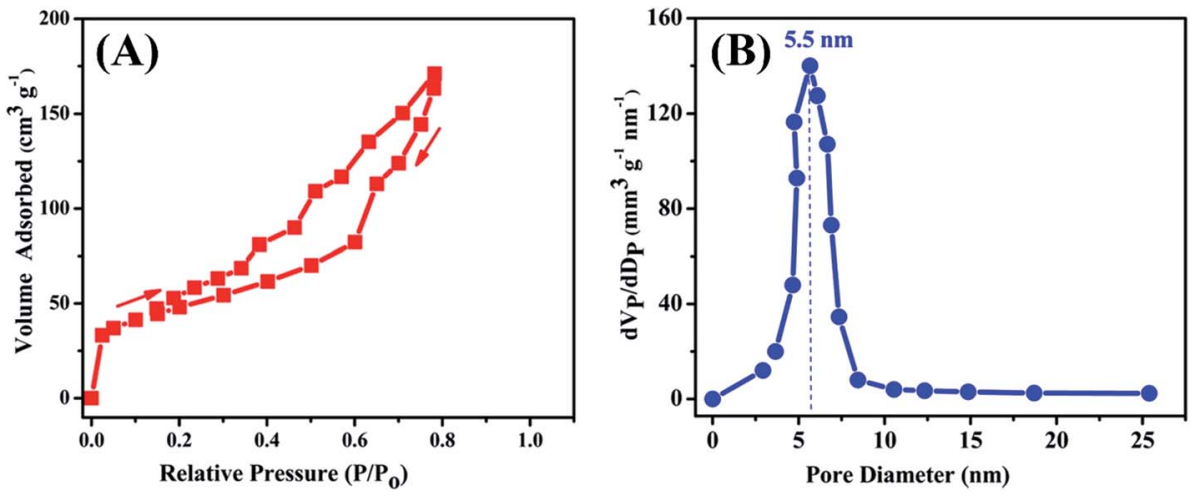

Fig. 4 (A) $\mathrm{N}_{2}$ adsorption-desorption isotherm and (B) pore size distribution curve of CoFeSe 2 nanorods using $\mathrm{BJH}$ method.

resulted to a better catalytic activity for hydrazine electrooxidation, later on. Furthermore, the TEM image (Fig. 5D) ensures the presence of rod type structures in the synthesized material with an average size of $40 \mathrm{~nm}$.

\section{EDX analysis}

EDX analysis was performed at randomly selected points over the surface of the prepared samples (Fig. S1†). Fig. 6A shows the EDX spectra of $\mathrm{CoFeSe}_{2}$ with resultant sharp peaks of Co, Fe, and Se elements. The considerable quantitative weight percentage was recorded for $\mathrm{Co}, \mathrm{Fe}$, and Se elements of about $19.26 \%, 1.21 \%$, and $59.91 \%$, respectively. The co-existence of $\mathrm{Co}, \mathrm{Fe}$, and Se presented the synergistic effect to form metal alloy NPs. Moreover, EDX mapping (Fig. 6B-E) of $\mathrm{CoFeSe}_{2}$ depicted the distribution of $\mathrm{Co}, \mathrm{Fe}$, and Se metals with the uniform dispersion.

Fig. 7 presents TPR profiles of the prepared nanocomposite. In general, two step reduction of cobalt oxide $\left(\mathrm{Co}_{3} \mathrm{O}_{4}\right)$ occurs as follows: ${ }^{36}$

$$
\begin{aligned}
& \mathrm{Co}_{3} \mathrm{O}_{4}+\mathrm{H}_{2} \rightarrow 3 \mathrm{CoO}+\mathrm{H}_{2} \mathrm{O} \\
& 3 \mathrm{CoO}+3 \mathrm{H}_{2} \rightarrow 3 \mathrm{Co}^{0}+3 \mathrm{H}_{2} \mathrm{O}
\end{aligned}
$$

\section{TPR analysis}

TPR profile of monometallic Co catalyst showed the 3 reduction peaks in the range of $150-800{ }^{\circ} \mathrm{C}$, respectively. The appearance of these reduction peaks can be attributed to the reduction of
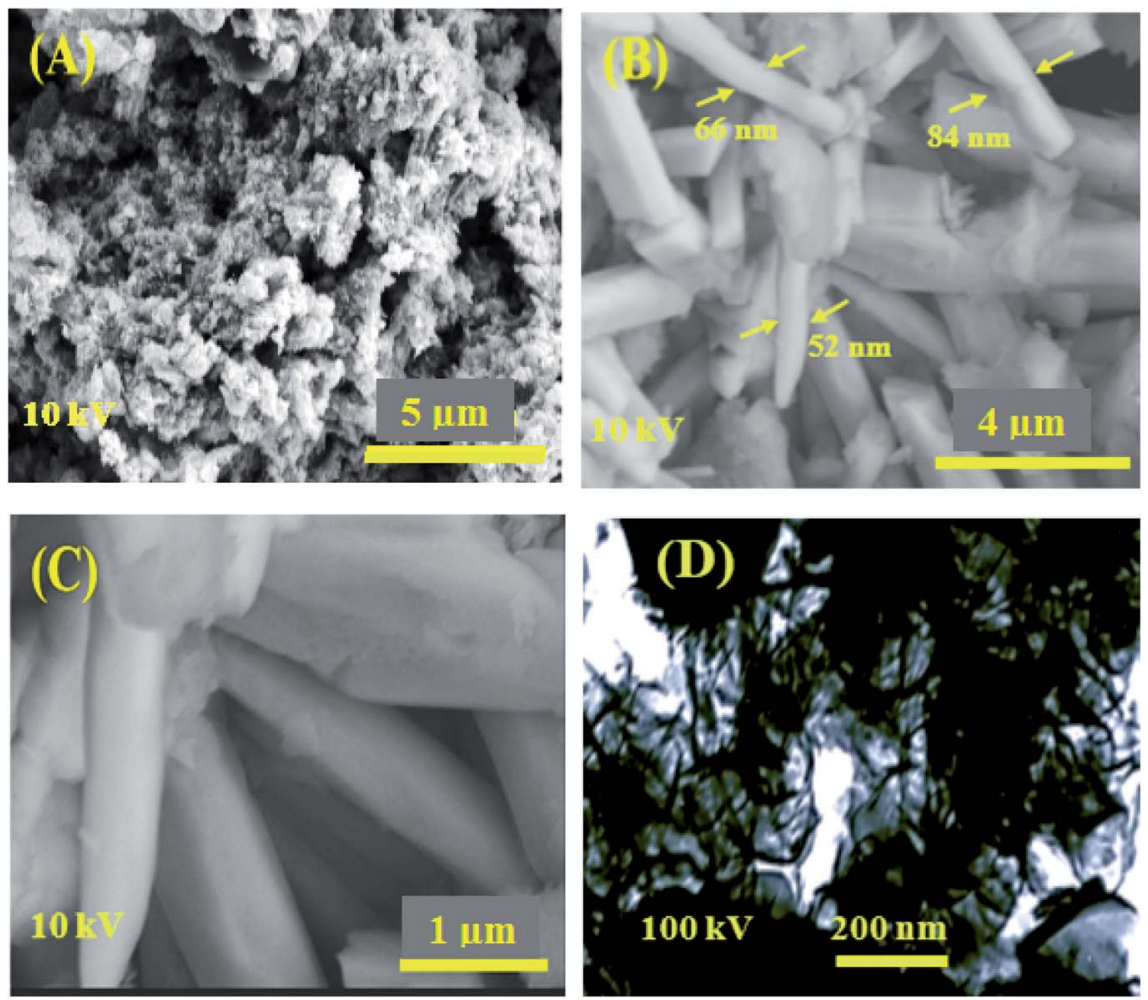

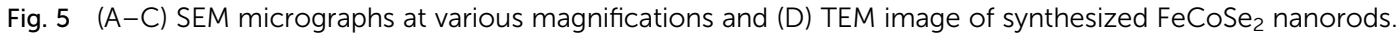




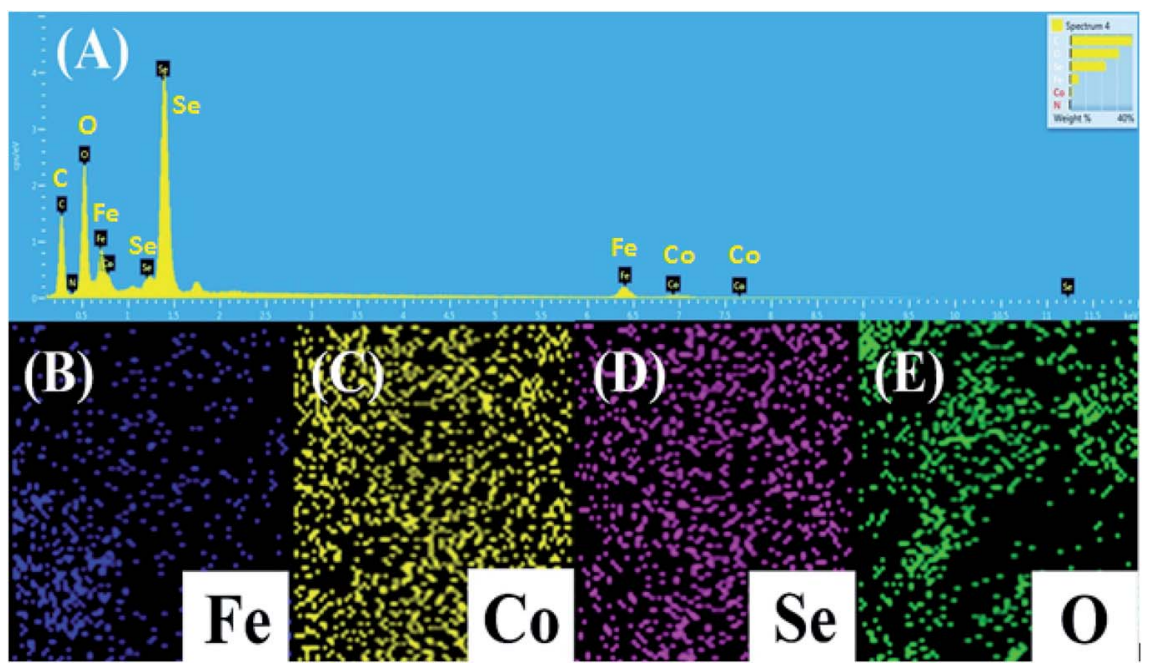

Fig. 6 (A) EDX profile for chemical composition and (B-E) EDX mapping for elemental distribution of the prepared CoFeSe 2 nanocomposite.

$\mathrm{Co}_{3} \mathrm{O}_{4}$ to $\mathrm{CoO}$ and further reduction of $\mathrm{CoO}$ to metallic $\mathrm{Co}^{\mathrm{o}} \cdot{ }^{37}$ In comparison, the $\mathrm{CoSe}_{2}$ catalyst presented ease in reduction behavior than that of the monometallic Co sample. In the case of $\mathrm{CoFeSe}_{2}$, the incorporation of $\mathrm{Fe}$ metal even in a small content led to a decline in the reduction temperature of cobalt oxide and reduction peaks were shifted towards lower temperature region. In this aspect, the present study suggested that the alloying effect of the constituent metals ( $\mathrm{Co}, \mathrm{Fe}$, and $\mathrm{Se}$ ) may promote the catalytic efficiency of $\mathrm{CoFeSe}_{2} / \mathrm{GCE}$ towards electrosensing of INZ. Overall, the synergistic effect might be accountable for the development in the field of catalysis.

\section{Active surface area measurements}

Voltammetric investigations of the $\mathrm{FeCoSe}_{2} / \mathrm{GCE}$ were performed using $5 \mathrm{mM}$ potassium ferrocyanide $\left(\mathrm{K}_{3}\left[\mathrm{Fe}(\mathrm{CN})_{6}\right] /\right.$ $\left.\mathrm{K}_{4}\left[\mathrm{Fe}(\mathrm{CN})_{6}\right]\right)$ solution as a redox probe. Fig. $\mathrm{S} 2 \uparrow$ shows the cyclic voltammograms recorded by using bare and modified GCE.

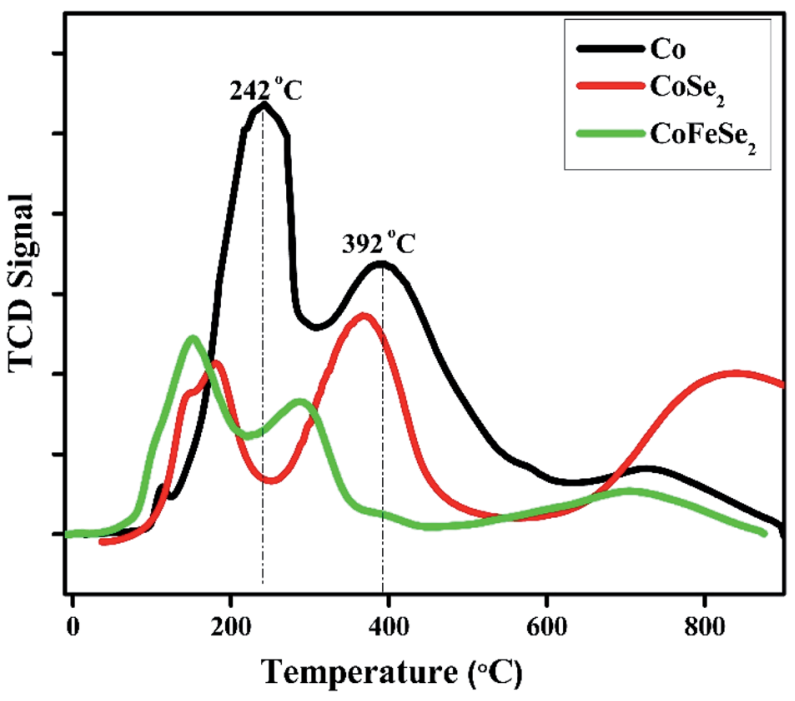

Fig. 7 TPR profiles of the synthesized nanocatalysts.
There were observed sharp peaks with a narrow peak potential difference and an obvious enhancement in the oxidationreduction peak currents in the $\mathrm{CV}$ of $\mathrm{FeCoSe}_{2} / \mathrm{GCE}$ compared to bare GCE, signifying rapid electron transfer process. ${ }^{38}$

The active surface area of the electrodes was estimated according to the Randles-Sevcik equation: $i_{\mathrm{pa}}=2.69 \times 10^{5} \mathrm{n}^{3 /}$ ${ }^{2} A D^{1 / 2} v^{1 / 2} \mathrm{C}$, where $A$ is the active surface area $\left(\mathrm{cm}^{2}\right), i_{\mathrm{pa}}$ is the redox peak current of potassium ferricyanide, $n$ is the number of electrons transferred ( 2 in this case), $D$ is the diffusion coefficient $\left(0.76 \times 10^{-5} \mathrm{~cm}^{2} \mathrm{~s}^{-1}, 25^{\circ} \mathrm{C}\right), v$ is the scan rate $\left(\mathrm{V} \mathrm{s}^{-1}\right)$ and $C$ is the concentration of analyte $(5 \mathrm{mM})$. The calculated active surface area of bare GCE and modified electrode are found to be $0.071 \mathrm{~cm}^{2}$ and $0.117 \mathrm{~cm}^{2}$, respectively. The larger active surface area is obtained for the modified electrode shows the greater electrochemical activity of the $\mathrm{FeCoSe}_{2} / \mathrm{GCE}$ as compare to bare GCE.

\section{Electrooxidation of INZ at FeCoSe $\mathrm{F}_{2} / \mathrm{GCE}$ modified electrode}

The electrocatalytic oxidation of Isoniazid was evaluated by SWASV technique. Fig. 8A shows the square wave voltammograms for the oxidation of INZ at bare and $\mathrm{FeCoSe}_{2} / \mathrm{GCE}$ in the BRB solution of $\mathrm{pH} 7$. At a potential of $0.45 \mathrm{~V}$, an oxidation signal for INZ was obtained by SWASV. The current response for INZ oxidation at $\mathrm{FeCoSe}_{2} / \mathrm{GCE}$ is manifestly promoted as compared to bare GCE. This enhancement in the current signal by using $\mathrm{FeCoSe}_{2} / \mathrm{GCE}$ is attributed to the larger active surface area, good conductivity, and excellent electrosensing potency of the $\mathrm{FeCoSe}_{2}$ nanorods. Fig. 8B shows the schematic presentation for electrochemical oxidation mechanism of INZ over modified FeCoSe $_{2} / \mathrm{GCE}^{39}$ These outcomes verified that the projected $\mathrm{FeCoSe}_{2} / \mathrm{GCE}$ is efficiently accomplished for the voltammetric sensing of INZ.

\section{Optimization of experimental parameters}

The $\mathrm{pH}$ of the medium has a pronounced effect on INZ detection and was observed using $\mathrm{FeCoSe}_{2} / \mathrm{GCE}$ by changing the $\mathrm{pH}$ of the solution from 4 to 8 as shown in Fig. 9A. It was seen that 

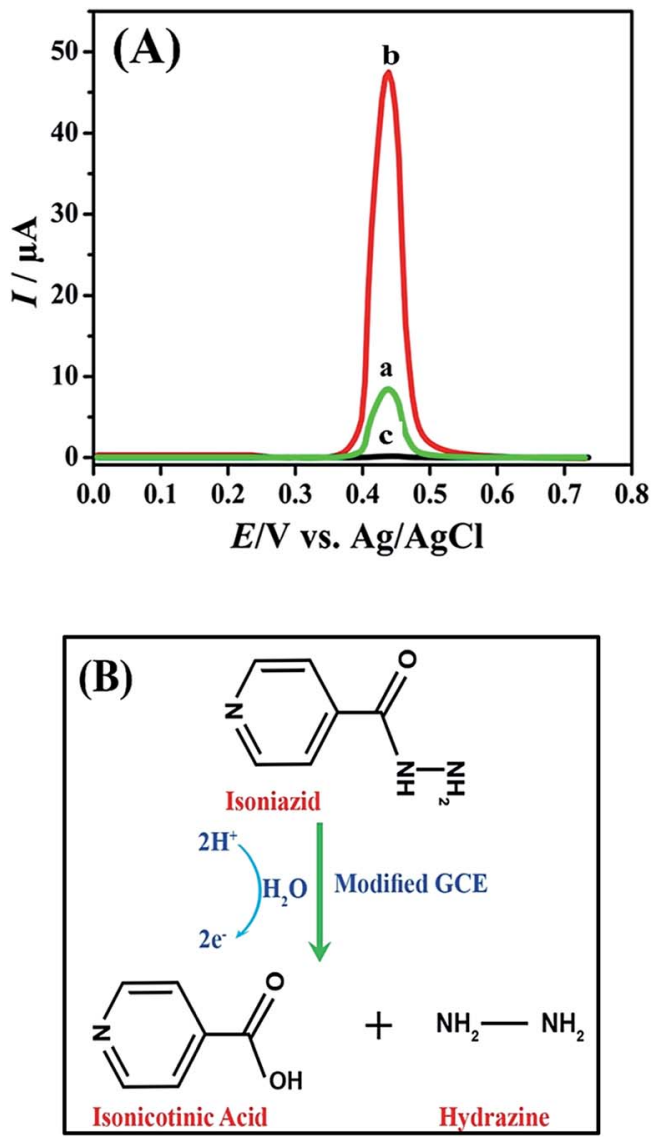

Fig. 8 (A) SWASV of (a) bare GCE in $25 \mu \mathrm{M}$ solution of INZ, (b) $\mathrm{FeCOSe}_{2} / \mathrm{GCE}$ in $25 \mu \mathrm{M}$ solution of INZ solution, and (c) $\mathrm{FeCOSe}_{2} / \mathrm{GCE}$ in solvent (BRB of $\mathrm{pH}$ 7) containing no INZ at a scan rate of $50 \mathrm{mV} \mathrm{s}^{-1}$, accumulation potential of $0.0 \mathrm{~V}$, and accumulation time of the $90 \mathrm{~s}$, and (B) electrochemical oxidation mechanism of INZ over modified $\mathrm{FeCOSe}_{2} / \mathrm{GCE}$.

the peak current value increases steadily with increasing the $\mathrm{pH}$ of the solution up to $\mathrm{pH} 7$ and then a steady fall in current response was recognized by further increasing $\mathrm{pH}$ of the solution. Hence, $\mathrm{pH} 7$ was optimized for further experimental work. Furthermore, a shift in peak potential for oxidation of INZ was observed in the negative direction with an increase in $\mathrm{pH}$ of the solution, signifying the direct involvement of the proton in electrode processes. Also, the slope value $52.48 \mathrm{mV}$ per unit $\mathrm{pH}$ was obtained from the plot of $E_{\mathrm{p}} v s$. pH (Fig. 9B) which demonstrates that the oxidation of INZ involves equal no of electrons and protons.

The effect of changing accumulation potential ( -0.4 to 0.3$)$ on the oxidation peak current of INZ was studied by SWASV as shown in Fig. S3A. $\dagger$ The oxidation peak current magnitude increases gradually towards positive potential direction until it reached its maximum value at $0.0 \mathrm{~V}$ thereafter, it decreased abruptly. So, an accumulation potential of $0.0 \mathrm{~V}$ was selected as optimum potential. The effect of accumulation time was also studied as shown in Fig. S3B. $\dagger$ It showed the enhancement in the peak current value up to $90 \mathrm{~s}$, afterward the current value declines with increasing time, and hence accumulation time of $90 \mathrm{~s}$ was selected for further experimental work.

Under optimized conditions calibration plot for INZ was achieved by SWASV in the concentration range of $0.03-1 \mu \mathrm{M}$ as shown in Fig. 10A. The results obtained showed a direct relation to the oxidation peak current against INZ concentration. The limit of detection (LOD) and limit of quantification (LOQ) for INZ detection were calculated by using eqn (3) and eqn (4), respectively

$$
\begin{aligned}
\mathrm{LOD} & =3 \mathrm{~s} / \mathrm{m} \\
\mathrm{LOQ} & =10 \mathrm{~s} / \mathrm{m}
\end{aligned}
$$

Here, " $s$ " is the standard deviation of the peak current of blank solution (three runs) and " $m$ " denotes the slope of current versus concentration plot. $^{40}$

Fig. 10B presents the effect of INZ concentration on its peak current response at the modified $\mathrm{FeCOSe}_{2} / \mathrm{GCE}$. From the linear relationship of the peak current and INZ concentration the LOD and LOQ with values of $1.24 \times 10^{-10} \mathrm{M}$ and $4.14 \times 10^{-10} \mathrm{M}$ were evaluated respectively. The regression data and various other parameters obtained from calibration curves are presented in Table S1. $\dagger$

\section{Stability and reproducibility of fabricated GCE}

To check the precision of the proposed method, repeatability and reproducibility of the fabricated GCE was investigated.
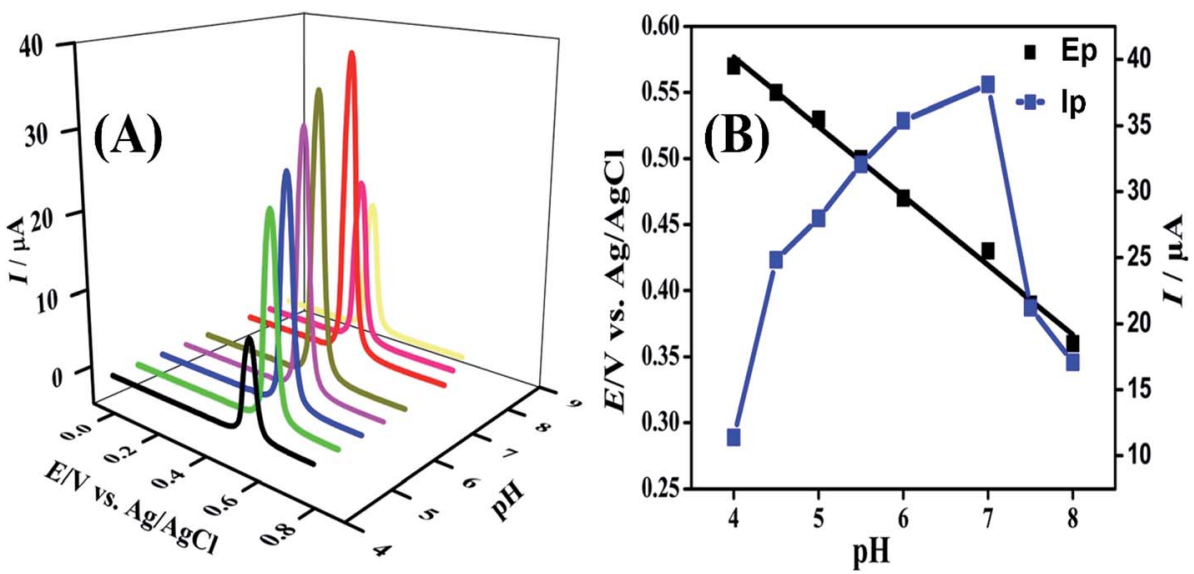

Fig. 9 (A) SWASV of $16 \mu \mathrm{M}$ solution of INZ using FeCoSe $2 / \mathrm{GCE}$ in 4-8 $\mathrm{pH}$ range and (B) Plots of $E_{\mathrm{p}}$ and $I_{\mathrm{p}} v s$. $\mathrm{pH}$. 

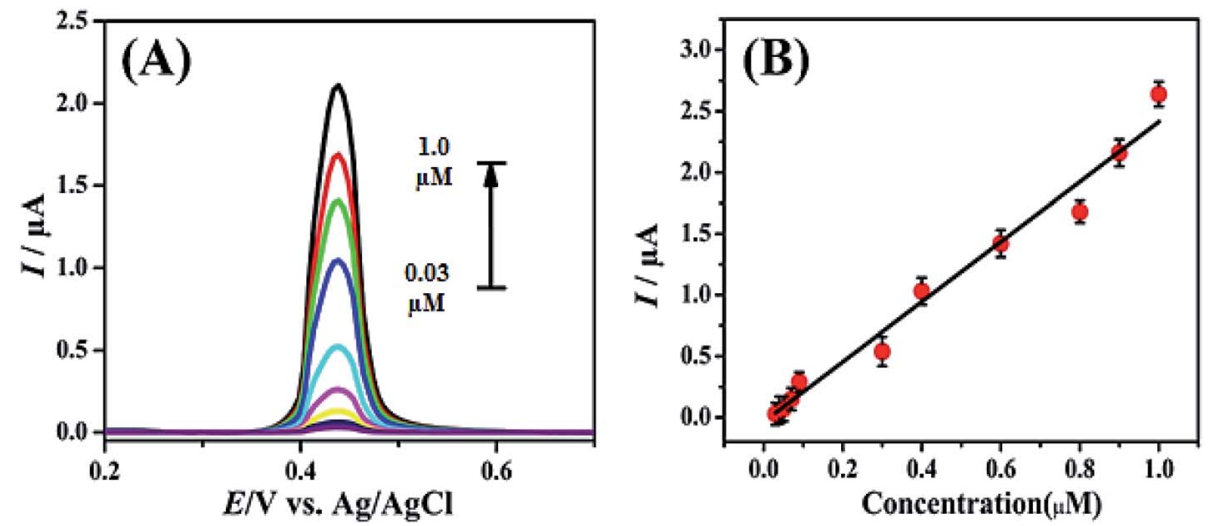

Fig. 10 (A) SWAS voltammograms of INZ in the concentration range of $0.03-1 \mu \mathrm{M}$ at FeCoSe $2 / \mathrm{GCE}$ in $\mathrm{BRB}$ solution (pH 7) under optimized conditions (scan rate of $50 \mathrm{mV} \mathrm{s}^{-1}$, accumulation potential of $0.0 \mathrm{~V}$, and accumulation time of $90 \mathrm{~s}$ and (B) the plot of $I_{\text {pa }}$ versus concentration.

The intra-day precision of the $\mathrm{FeCoSe}_{2} / \mathrm{GCE}$ was checked by performing three repeated measurements within a day and the $\%$ RSD was found to be $2.22 \%$. The stability based on inter-day precision was checked by performing three repeated measurements between days by SWASV technique and the \% RSD was found to be $0.56 \%$. The relative standard deviation (\% RSD) was calculated for isoniazid detection and found to be in acceptable range i.e., less than $5 \%$ as shown in Fig. S4. $\dagger$ The results achieved specify that the $\mathrm{FeCoSe}_{2} / \mathrm{GCE}$ have good precision, thus can be employed for sensitive and selective detection of INZ.

\section{Interference study}

In order to study the interference of various interferences, which commonly exist in the biological samples, some interference experiments were performed as shown in Fig. S5. $\dagger$ It was observed that 500 folds' excess of $\mathrm{Ca}^{2+}, \mathrm{NH}^{4+}, \mathrm{Mg}^{2+}$, glucose, 200 folds of ascorbic acid and uric acid, showed almost no interference to anodic peak current response of INZ (RSD = $1.59 \%$ ). The interference experiment showed that the fabricated GCE has the ability of anti-jamming. The comparison of this work with reported modified electrodes for INZ detection is summarized in Table 1.

\section{Practical application of $\mathrm{FeCoSe}_{2} / \mathrm{GCE}$ for INZ analysis}

To check the practical applicability of the $\mathrm{FeCoSe}_{2} / \mathrm{GCE}$, the analyte INZ was assessed in physiological fluids i.e., in human serum and urine samples by applying SWASV technique. Detection of drugs in physiological fluids can help in following their metabolic fate. The biological fluids were originally taken

Table 1 Comparison of analytical parameters of our modified FeCoSe 2 /GCE electrode with reported ones for the determination of isoniazid using various techniques

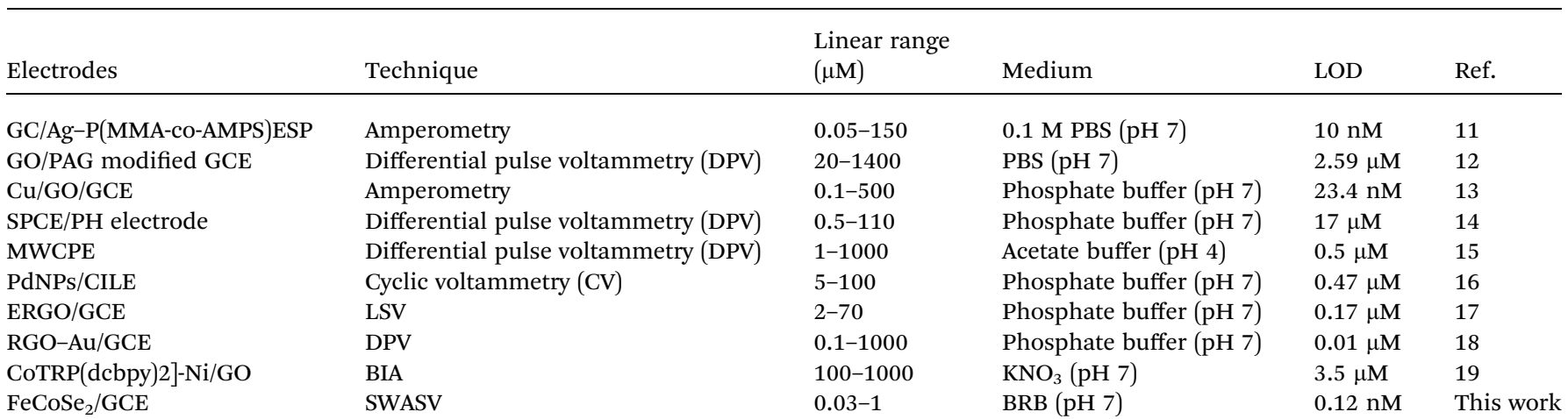

Table 2 INZ determination in real samples (urine and human serum) by proposed SWASV technique

\begin{tabular}{lllrl}
\hline Sample & Analyte & INZ conc. added $(\mu \mathrm{M})$ & $\begin{array}{l}\text { INZ conc. detected } \\
(\mu \mathrm{M})\end{array}$ & $\begin{array}{l}\text { Recovery } \\
(\%)\end{array}$ \\
\hline Urine & INZ & 5 & 4.94 & $\begin{array}{l}\text { RSD }(\%) \\
(n=3)\end{array}$ \\
Human serum & INZ & 2 & 1.96 & 98.8 \\
\end{tabular}


from a healthy volunteer. Each biological sample was diluted up to 15 times by using BRB of $\mathrm{pH} 7$ and then spiked by INZ under commonly used standard addition methods. Each sample was analyzed three times $(n=3)$ to check the reproducibility. The recovery results obtained for spiked INZ samples by using $\mathrm{FeCoSe}_{2} / \mathrm{GCE}$ showed a very low RSD value of $2.5 \%$ and $3.4 \%$ for urine and human serum samples, respectively. This outcome validated that the $\mathrm{FeCoSe}_{2} / \mathrm{GCE}$ has its specific extensive reliability towards detection of INZ in biological fluids. The findings of the real sample analyses are listed in Table 2.

\section{Conclusions}

In the present work $\mathrm{FeCOSe}_{2}$ modified GCE was successfully fabricated and used for electrochemical determination of isoniazid. The $\mathrm{FeCoSe}_{2}$ GCE showed figures of merit in the context of wider linear range, lower limit of detection and strong resilience to interfering agents. Owning to the exceptional properties of $\mathrm{FeCoSe}_{2}$, it offers an enhanced oxidation response of INZ in neutral medium. The higher sensitivity and lower detection limit are attributed to good conductivity, larger surface area, excellent catalytic properties and amplification effect of $\mathrm{FeCoSe}_{2}$ nanorods. The $\mathrm{FeCoSe}_{2} / \mathrm{GCE}$ also displayed great potential application for INZ detection in human serum and urine samples with acceptable recoveries. The robust performance of $\mathrm{FeCoSe}_{2} / \mathrm{GCE}$ bimetallic catalysts would be correlated to the synergistic effect of constituent metals, crystallinity, unique morphology (nanorods), uniform dispersion of alloy particles, narrow pore size distribution, and presence of more active sites as ensured by XRD, SEM, TEM, EDX, and TPR analyses.

\section{Ethical statement}

This article does not contain any direct studies on human participants and animals. The experiments were performed in compliance with the relevant laws and institutional guidelines of Quaid-i-Azam University, Islamabad, with prior approval from the ethical committee. Only the assay corresponding to practical testing of the designed sensor includes the use of urine and human serum. The urine sample was obtained with informed consent of the healthy donor and according to institutional guidelines. While the drug free synthetic human serum was purchased from Sigma Aldrich.

\section{Conflicts of interest}

There are no conflicts to declare.

\section{Acknowledgements}

Authors are highly thankful to Quaid-i-Azam University and Higher Education Commission of Pakistan for providing the research facility. Authors gratefully acknowledge the Deanship of Scientific Research (DSR), King Abdulaziz University, Jeddah, Saudi Arabia for supporting this work under grant no. (KEP-1130-41).

\section{References}

1 S. Hammi, K. E. Ataouna, K. Bouti, O. Elbouazzi, M. Laine and J. E. Bourkadi, Importance of Therapeutic Drug Monitoring in the Treatment of Active Tuberculosis - A Retrospective Study of 4 Cases, Int. J. Surg. Med., 2016, 3, 10.

2 J. Rosa, T. C. Machado, A. K. D. Silva, G. Kuminek, A. J. Bortolluzzi, T. Caon and S. G. Cardoso, IsoniazidResveratrol Cocrystal: A Novel Alternative for Topical Treatment of Cutaneous Tuberculosis, Cryst. Growth Des., 2019, 19, 5029.

3 U. P. Azad and V. Ganesan, Efficient electrocatalytic oxidation and selective determination of isoniazid by Fe(tmphen) $32+$-exchanged Nafion ${ }^{\circledR}$-modified electrode, $J$. Solid State Electrochem., 2012, 16, 2907.

4 B. G. Mahmoud, M. Khairy, F. A. Rashwan and C. E. Banks, Simultaneous Voltammetric Determination of Acetaminophen and Isoniazid (Hepatotoxicity-Related Drugs) Utilizing Bismuth Oxide Nanorod Modified ScreenPrinted Electrochemical Sensing Platforms, Anal. Chem., 2017, 89, 2170.

5 M. Khuhawar, Liquid chromatographic determination of isoniazid, pyrazinamide and rifampicin from pharmaceutical preparations and blood, J. Chromatogr. B, 2002, 766, 357.

6 L. Toit, V. Pillay and Y. Choonara, A Mathematical Approach for the Simultaneous In Vitro Spectrophotometric Analysis of Rifampicin and Isoniazid from Modified-Release Anti-TB Drug Delivery Systems, Curr. Drug Delivery, 2010, 7, 5.

7 P. R. Chellini, T. O. Mendes, P. H. Franco, B. L. Porto, V. K. Tippavajhala, I. C. César, M. A. Oliveira and G. A. Pianetti, Simultaneous determination of rifampicin, isoniazid, pyrazinamide and ethambutol in 4-FDC tablet by Raman spectroscopy associated to chemometric approach, Vib. Spectrosc., 2017, 90, 14.

8 M. A. Lomillo, R. O. Domínguez and M.' Mj. Arcos, Resolution of ternary mixtures of rifampicin, isoniazid and pyrazinamide by differential pulse polarography and partial least squares method, Anal. Chim. Acta, 2001, 449, 167.

9 M. Ghoneim, K. El-Baradie and A. Tawfik, Electrochemical behavior of the antituberculosis drug isoniazid and its square-wave adsorptive stripping voltammetric estimation in bulk form, tablets and biological fluids at a mercury electrode., J. Pharm. Biomed. Anal., 2003, 33, 673.

10 X. Yan, X. Bo and L. Guo, Electrochemical behaviors and determination of isoniazid at ordered mesoporous carbon modified electrode., Sens. Actuators, B, 2011, 155, 837.

11 P. K. Rastogi, V. Ganesan and U. P. Azad, Electrochemical determination of nanomolar levels of isoniazid in pharmaceutical formulation using silver nanoparticles decorated copolymer, Electrochim. Acta, 2016, 188, 818.

12 B. Devadas, S. Cheemalapati, S.-M. Chen, M. A. Ali and F. M. A. Al-Hemaid, Highly sensing graphene oxide/polyarginine-modified electrode for the simultaneous 
electrochemical determination of buspirone, isoniazid and pyrazinamide drugs, Ionics, 2014, 21, 547.

13 T. S. Balamurugan, K. Manibalan, S.-T. Huang, P. Balasubramnian and S. M. Chen, High Sensitive Electrochemical Quantification of Isoniazid in Biofluids Using Copper Particles Decorated Graphene Oxide Nano Composite, Int. J. Electrochem. Sci., 2017, 12, 9150.

14 M. F. Bergamini, D. P. Santos and M. V. B. Zanoni, Determination of isoniazid in human urine using screenprinted carbon electrode modified with poly-L-histidine, Bioelectrochemistry, 2010, 77, 133.

15 S. Shahrokhian and M. Amiri, Multi-walled carbon nanotube paste electrode for selective voltammetric detection of isoniazid, Microchim. Acta, 2006, 157, 149.

16 G. Absalan, M. Akhond, M. Soleimani and H. Ershadifar, Efficient electrocatalytic oxidation and determination of isoniazid on carbon ionic liquid electrode modified with electrodeposited palladium nanoparticles, J. Electroanal. Chem., 2016, 761, 1.

17 S. Cheemalapati, S. Palanisamy and S.-M. Chen, Electrochemical determination of Isoniazid at electrochemically reduced graphene oxide modified electrode, Int. J. Electrochem. Sci., 2013, 8, 3953.

18 Z. Guo, Z.-Y. Wang, H.-H. Wang, G.-Q. Huang and M.-M. Li, Electrochemical sensor for Isoniazid based on the glassy carbon electrode modified with reduced graphene oxideAu nanomaterials, Mater. Sci. Eng., C, 2015, 57, 197.

19 J. S. Aguirre-Araque, J. M. Goncalves, M. Nakamura, P. O. Rossini, L. Angnes, K. Araki and H. E. Toma, GO composite encompassing a tetraruthenated cobalt porphyrin-Ni coordination polymer and its behavior as isoniazid BIA sensor, Electrochim Acta, 2019, 300, 113.

20 M. F. Bergamini, D. P. Santos and M. V. Zanoni, Determination of isoniazid in human urine using screenprinted carbon electrode modified with poly-L-histidine., Bioelectrochemistry, 2010, 77, 133.

21 S. Mani, S. Ramaraj, S.-M. Chen, B. Dinesh and T.-W. Chen, Two-dimensional metal chalcogenides analogous $\mathrm{NiSe}_{2}$ nanosheets and its efficient electrocatalytic performance towards glucose sensing., J. Colloid Interface Sci., 2017, 507, 378.

22 Y.-R. Zheng, M.-R. Gao, Q. Gao, H.-H. Li, J. Xu, Z.-Y. Wu and S.-H. Yu, An Efficient $\mathrm{CeO}_{2} / \mathrm{CoSe}_{2}$ Nanobelt Composite for Electrochemical Water Oxidation, Small, 2015, 11, 182.

23 L. Mi, H. Sun, Q. Ding, W. Chen, C. Liu, H. Hou, Z. Zheng and C. Shen, 3D hierarchically patterned tubular NiSe with nano-/microstructures for $\mathrm{Li}$ ion battery design, Dalton Trans., 2012, 41, 12595.

24 A. Eftekhari, Molybdenum diselenide $\left(\mathrm{MoSe}_{2}\right)$ for energy storage, catalysis, and optoelectronics, Appl. Mater. Today, 2017, 8, 1.

25 S. M. Tan, Z. Sofer, J. Luxa and M. Pumera, AromaticExfoliated Transition Metal Dichalcogenides: Implications for Inherent Electrochemistry and Hydrogen Evolution, ACS Catal., 2016, 6, 4594.

26 M. Gilic, M. Petrovic, J. Cirkovic, N. Paunovic, S. Savic-Sevic, Z. Nikitovic, M. Romcevic, I. Yahia and N. Romcevic, Low- temperature photoluminescence of $\mathrm{CuSe}_{2}$ nano-objects in selenium thin films, Process. Appl. Ceram., 2017, 11, 127.

27 C.-H. Ding, J.-J. Tang, S. Chen, Z.-Q. Liu and N. Li, $\mathrm{Co}_{0.85} \mathrm{Se} /$ Multi-Walled Carbon Nanotube Composite as Alternative Cathode Catalyst for Microbial Fuel Cells, J. Nanosci. Nanotechnol., 2017, 17, 1438.

28 A. K. Dutta, S. K. Maji, A. Mondal, B. Karmakar, P. Biswas and B. Adhikary, Iron selenide thin film: peroxidase-like behavior, glucose detection and amperometric sensing of hydrogen peroxide, Sens. Actuators, B, 2012, 173, 724.

29 T. J. Theerthagiri, R. Sudha, K. Premnath, P. Arunachalam, J. Madhavan and A. M. Al-Mayouf, Growth of iron diselenide nanorods on graphene oxide nanosheets as advanced electrocatalyst for hydrogen evolution reaction., Int. J. Hydrogen Energy, 2017, 42, 13020.

30 B. Yu, J. Jin, H. Wu, S. Wang, Q. Xia and H. Liu, Iron and nickel doped $\mathrm{CoSe}_{2}$ as efficient non precious metal catalysts for oxygen reduction., Int. J. Hydrogen Energy, 2017, 42, 236.

31 A. K. Singh and Q. Xu, Synergistic catalysis over bimetallic alloy nanoparticles, ChemCatChem, 2013, 5, 652.

32 Y.-R. Zheng, M.-R. Gao, Z.-Y. Yu, Q. Gao, H.-L. Gao and S.-H. Yu, Cobalt diselenide nanobelts grafted on carbon fiber felt: an efficient and robust 3D cathode for hydrogen production, Chem. Sci., 2015, 6, 4594.

33 B. Liu, Y.-F. Zhao, H.-Q. Peng, Z.-Y. Zhang, C.-K. Sit, M.-F. Yuen, T.-R. Zhang, C.-S. Lee and W.-J. Zhang, Electrocatalysts: Nickel-Cobalt Diselenide 3D Mesoporous Nanosheet Networks Supported on Ni Foam: An All-pH Highly Efficient Integrated Electrocatalyst for Hydrogen Evolution, Adv. Mater., 2017, 29, 19.

34 Y.-R. Zheng, P. Wu, M.-R. Gao, X.-L. Zhang, F.-Y. Gao, H.-X. Ju, R. Wu, Q. Gao, R. You, W.-X. Huang, S.-J. Liu, S.-W. Hu, J. Zhu, Z. Li and S.-H. Yu, Doping-induced structural phase transition in cobalt diselenide enables enhanced hydrogen evolution catalysis., Nat. Commun., 2018, 9, 1.

35 K. S. W. Sing, Reporting physisorption data for gas/solid systems with special reference to the determination of surface area and porosity (Recommendations 1984), Pure Appl. Chem., 1985, 57, 603.

36 G. S. Sewell, S. E. Van and C. T. O'Connor, Use of TPR/TPO for characterization of supported cobalt catalysts, Catal. Lett., 1996, 37, 255.

37 H.-Y. Lin and Y.-W. Chen, The mechanism of reduction of cobalt by hydrogen, Mater. Chem. Phys., 2004, 85, 171.

38 B. Yu, J. Jin, H. Wu, S. Wang, Q. Xia and H. Liu, Iron and nickel doped $\mathrm{CoSe}_{2}$ as efficient non precious metal catalysts for oxygen reduction, Int. J. Hydrogen Energy, 2017, 42, 236.

39 R. Chokkareddy, N. K. Bhajanthri and G. G. Redhi, An enzyme-induced novel biosensor for the sensitive electrochemical determination of isoniazid, Biosensors, 2017, 7, 21.

40 M. S. Quintino and L. Angnes, Fast BIA-amperometric determination of isoniazid in tablets, J. Pharm. Biomed. Anal., 2006, 42, 400. 